\title{
Docência e climatologia na disciplina de Geografia do segundo segmento do ensino fundamental da rede municipal de educação de Campos dos Goytacazes: uma aproximação
}

\section{Teaching and climatology in the discipline of Geography of the second segment of the elementary education of the municipal education network of Campos dos Goytacazes: an approach}

\author{
Mayra Barros da Silva'(i), Denizart Silva Fortuna"(i) \\ ' Universidade Federal Fluminense, Campos dos Goytacazes, RJ, Brasil \\ " Universidade Federal Fluminense, Departamento Sociedade, Educação e Conhecimento,Niterói, RJ, \\ Brasil
}

\section{RESUMO}

O intuito da investigação que ora se apresenta na forma de artigo tem a pretensão de conhecer as representações curriculares veiculadas por aqueles que se dedicam à aprendizagem da climatologia nas aulas de geografia do segundo segmento do fundamental da rede escolar oficial do município de Campos dos Goytacazes, norte fluminense. Neste momento, a divulgação preliminar dos seus resultados conta com os depoimentos dos sujeitos responsáveis pelo seu ensino no ano de 2019. Especificamente, o objetivo é a apreensão das representações sociais desses docentes sobre a climatologia enquanto conhecimento escolar. No tocante aos aspectos teórico-metodológicos, a abordagem empreendida foi pela Teoria das Representações Sociais, de Moscovici (2012) e Análise do Conteúdo, de Bardin (2004). Nesse sentido, a pesquisa de cunho qualitativo tem como estrutura a apreensão da noção de conhecimento escolar seguida da análise do arcabouço legislativo dos currículos para, finalmente, a interpretação dos depoimentos do professorado. O resultado traz como sugestão a necessidade de mais pesquisas no que diz respeito à profissionalização promovida pelos cursos de formação de professores, além das demandas específicas de políticas públicas não só de formação continuada, mas também de apoio para a realização de diferentes metodologias e estratégias de ensino por parte da Secretaria Municipal de Educação de Campos dos Goytacazes.

Palavras-chave: Climatologia Escolar; Conhecimento Escolar; Teoria da Representação Social; Ensino de Geografia 


\section{ABSTRACT}

The purpose of the investigation presented in the form of an article is to understand the teacher's curricular representation about learning Climatology in Geography classes in the second part of "fundamental education" (ensino fundamental) of the official schools in Campos dos Goytacazes northern Rio de Janeiro. At this time, the preliminary disclosure of their results relies on the subjects' testimonies responsible for their teaching in 2019. Specifically, the objective is to apprehend the social representations of these teachers about climatology as school knowledge. Regarding the theoretical and methodological aspects, the approach taken was by the Theory of Social Representations, by Moscovici (2012) and Analysis of Content, by Bardin (2004). In this sense, the qualitative research has as structure the apprehension of the notion of school knowledge followed by the analysis of the legislative framework of the curricula for, finally, the interpretation of the professors' testimonies. The result suggests the need for more research about the professionalization promoted by teacher training courses and the specific demands of municipality public policies, not only for continuing education but also for supporting the realization of different methodologies and teaching strategies

Keywords: School Climatology; School Knowledge; Theory of Social Representation; Geography Teaching

\section{INTRODUÇÃO}

É sabido que uma das características do "fazer ciência" é a não linearidade. Mesmo assim, é instigante o resgate do jornalista David Wallace-Wells (2019) sobre alguns termos oriundos dos estudos científicos de tempos atrás. Ele conta que, na década de 50 do século passado, o físico estadunidense Roger Revelle foi o primeiro a anunciar o aquecimento global (global warming). Antes disso, a expressão efeito estufa (greenhouse effect) já fora inaugurada, precisamente, em 1850 quando John Tyndall e Eunice Foote estudaram os efeitos da arrancada industrial dos EUA correlacionados ao aumento da temperatura. Essas análises ainda não remetiam à hecatombe que as mudanças climáticas em escala global poderiam causar, aliás, bem distintas dos estudos de especialistas de diferentes países quando divulgados em artigos científicos e pronunciados por diversos meios de divulgação nos tempos de hoje.

Diante desse quadro de consequências catastróficas no âmbito socioeconômico, (geo)político, cultural e ambiental, a climatologia é evidenciada, especialmente diante dos fundamentos das narrativas alarmistas ("Terra Nenhuma") ou da hipótese da Meia-Terra habitável (WILSON apud WELLS-WALLACE, 
2019). Tais narrativas, por sua vez, não deixam de "atravessar" o cotidiano escolar, embora a climatologia sob o olhar geográfico esteja nas grades curriculares escolares há muito tempo, aliás, por isso presente em manuais didáticos e em atlas geográficos escolares mesmo que em diferentes abordagens (FORTUNA, 2015).

O reconhecimento desse desdobramento no cotidiano escolar é demonstrado com as recentes pesquisas educacionais e com o contato permanente com professores escolares graças ao trabalho com formação docente no ensino superior nos últimos 15 anos. Outrossim, os questionamentos e as dúvidas entre os licenciandos sobre "como se deve dar uma aula?" não são menos importantes. Ademais, o debate sobre as mudanças climáticas está cada vez mais presente nas agendas político-partidárias nacionais - não livre de controvérsias - e seu caráter é global.

Com efeito, os desafios epistemológicos, didáticos e curriculares da climatologia geográfica é um convite à reflexão das formas de abordagem pedagógica pelos seus professores. Por conta desses desafios, justifica-se a motivação para esta investigação que ora se apresenta em resultados preliminares. Diante dos levantamentos realizados com professores atuantes no segundo segmento do ensino fundamental na rede municipal de ensino de Campos dos Goytacazes (RJ) em 2019, o mote foi compreender o significado atribuído ao conteúdo de climatologia pelos professores atuantes na disciplina mediante as práticas pedagógicas engendradas em seu ofício.

Tal consideração é uma interpretação dos registros obtidos graças ao cunho qualitativo da pesquisa. Assim, a investigação cumpriu as etapas da categorização, descrição e interpretação de dados (SANTOS et al., 2014) mediadas pela Análise de Conteúdo, de Bardin (1977) como parte do aporte metodológico. A Teoria das Representações Sociais, de Moscovici (2012), colaborou com a compreensão do significado da validade da climatologia como elemento curricular da disciplina de geografia, não necessariamente de acordo com as pretensões dos currículos oficiais. A organização do texto que ora se inicia está dividido em (1) definição dos 
parâmetros da relação entre conteúdo da climatologia geográfica, conhecimento escolar e mediação didática; (2) pesquisa documental para compreender as especificidades desse conteúdo em documentos regulamentadores e normatizadores a partir da Lei de Diretrizes e Bases da Educação Nacional (LDB), de 1996, e dos Parâmetros Curriculares Nacionais, de 1998, ainda em vigor no momento do levantamento para, finalmente, (3) a realização e análises das apreensões e significados do conteúdo em tela graças às entrevistas semiestruturadas com professores atuantes e ligados à Secretaria Municipal de Educação de Campos dos Goytacazes (RJ).

\section{CONHECIMENTO ESCOLAR: PARA QUE SERVE A CLIMATOLOGIA ESCOLAR NAS AULAS DE GEOGRAFIA?}

O extenso levantamento bibliográfico privilegiou os estudos que justificassem os ensinamentos da climatologia geográfica enquanto conteúdo escolar e que problematizassem o seu ensino em parte da educação básica. Então, do campo de estudos do Ensino de Geografia, autores como Cavalcanti (2010, 2013), Maia (2018), Callai (2010), Fortuna (2015), Pontuschka (2002), Steinke (2012, 2014, 2015) são uníssonos em afirmar que os conceitos e processos correlacionados ao assunto são fundamentais para compreender a organização espacial.

Callai (2010), por exemplo, ratifica a necessidade da clareza da finalidade da sua aprendizagem. Em suas palavras:

[...] A Geografia sendo a disciplina que estuda a sociedade a partir da abordagem espacial, analisa o espaço que apresenta a concretização/materialização das relações que acontecem entre os homens e destes com a natureza. Os elementos e os fatores geográficos são fenômenos datados e situados e como tal trazem em si todas as contradições advindas da vida social demarcada temporalmente e espacialmente. Isto quer dizer que são necessários aportes teóricos que 
encaminhem e auxiliem a interpretação da realidade [...] (CALLAI, 2010, p. 17).

Se os objetivos educacionais estiverem bem definidos nem assim seriam suficientes para a o desenvolvimento pleno da racionalidade espacial dos educandos. Baseando-se em pesquisas de Steinke (2015), há fortes indícios de que aqueles objetivos educacionais estejam promovendo um saber descontextualizado dos cotidianos estudantis. Ela afirma que:

[...] a abordagem do conteúdo de climatologia nas escolas tem se apresentado como um saber descontextualizado da realidade dos alunos e da real perspectiva geográfica do clima, pois, [...] os conteúdos são expostos de forma estática, sem ligação com os saberes prévios dos alunos e com sua realidade local e sem procurar investigar o significado do clima para as diferentes sociedades [...]" (STEINKE, 2015, p. 236).

Vale enfatizar que a própria concepção da climatologia sofreu diversas alterações e transformações desde o seu reconhecimento como saber científico. Novas teorizações para novos "achados" contam com as inovações metodológicas reforçando as argumentações em favor de que novos padrões atmosféricos também seriam provocados pelas atividades sociais.

A mesma autora já citada pondera:

[...] A falta de entendimento ou conhecimento dos temas relacionados à Climatologia por parte dos professores e alunos, é algo assustadoramente aparente. Essa questão tem sido elemento de pesquisa e discussão de alguns estudiosos de Geografia. Os argumentos que levam à constatação são, principalmente a pequena carga horária do discente de geografia, falta de material, a má formação do professor, a pouca estrutura oferecida pelas escolas e os baixos salários pagos aos professores. Todos esses fatores contribuem para pouca relevância dada a esse tema na escola, o que muito surpreende, já que muitos assuntos relacionados ao clima e ao tempo são tratados diariamente na mídia escrita e falada [...] (id., ibidem, p. 239)

Ao final da década de 90, Zavattini (1998) já destacava a necessidade da atenção ao futuro do ensino da Climatologia nos cursos de Geografia ao indagar as abordagens da didática da climatologia na formação de professores. Sobre as 
obras utilizadas nas aulas, ele indagava acerca dos problemas que estavam sendo pesquisados e sugerido aos alunos.

A preocupação do autor centrava-se na maneira como o conhecimento em análise sob o enfoque geográfico nos cursos de (pós)graduação seriam desenvolvidos, sobretudo os conceitos e fenômenos físico-químicos. O autor ainda defendia os programas de iniciação científica como uma das alternativas para os licenciandos adquirirem competências da formação científica.

Mais recente, outra pesquisa na área de Climatologia Geográfica, dessa vez, centrada na mediação pedagógica empreendida pelos professores pôs em relevo o "hiato" entre o conhecimento climatológico geográfico e os pedagógicos nas práticas docentes no mesmo recorte territorial deste trabalho. Fortuna (2012) considerou que o "distanciamento", segundo levantamento realizado, estaria na formação inicial de professores em sua grande parte: " o ensino da climatologia é dissociado dos conceitos e fenômenos geográficos assim como outras disciplinas acadêmicas ligadas ao campo da geografia física" (2012, p. 80).

Reconhece-se que os conteúdos que envolvem o ensino da Climatologia Geográfica não são simples haja vista o embasamento científico necessário proveniente da Meteorologia, além do pedagógico. É válido destacar ainda que se por um lado a mídia em geral e as redes sociais também são veículos de divulgação e informação, a problematização entre o saber científico e o pedagógico torna-se ainda mais importante nas instituições de formação docente, porque a precisão conceitual e o rigor metodológico a se oferecer enquanto conteúdos curriculares podem ser colocados à prova diante de distintos contextos ou realidades escolares.

Sem embargo, o mesmo autor, em outro trabalho baseado em estudos do campo educacional chama atenção para a necessidade do reconhecimento e da problematização dos saberes escolares. Compreende-se que o saber dito científico da climatologia sofre um processo de transformação significativa ao se tornar em 
conhecimento ensinável1. Desse modo, pode-se falar que o ensino escolar tem como uma de suas referências o conhecimento produzido pelas instituições de pesquisa/universidades, mas não é uma relação de identidade e muito menos única. De um modo geral, não se trata de mera adaptação do conteúdo para outros públicos (LOPES, 1997; GABRIEL, 2001; MARANDINO, 2003).

Por essa razão, é possível afirmar que a existência de uma epistemologia escolar serve para tratar da problemática da construção dos saberes escolares mediante o reconhecimento da especificidade de suas condições de produção, de transmissão e de contexto. É possível ainda considerar que ela pressupõe a assunção de uma epistemologia plural, aberta ao reconhecimento das diferentes formas de racionalidade e de validade do conhecimento (GABRIEL, 2001). Voltandose à passagem alhures, é importante refletir se um programa de formação "científica" nos cursos de licenciatura que não venha a discutir a constituição e o teor do conhecimento da escola em suas diferentes abordagens educativas seria útil para a formação (inicial) docente.

Nesse sentido, a escola não seria somente um local onde os alunos convivem e aprendem, onde acontecem interações sociais específicas que delimitam a comunidade escolar ou ainda onde configurariam relações de poder específicas (por exemplo, aquelas entre docente e discente). Ela pode ser tudo isso, além do entendimento de que é uma instituição da modernidade cuja gestão se volta também à transmissão e produção de determinados saberes, de representações sociais e de símbolos (FORQUIN, 1993). É um espaço institucional onde se produz identidades e possibilidades onde o caráter científico do conhecimento é ressignificado2.

\footnotetext{
1 PIMENTA (2019) esclarece que "[...] o foco da Didática dentro dos processos de ensino passa a ser a mobilização dos sujeitos para elaborarem a construção/reconstrução de conhecimentos e saberes. Assim, mais complexo que elaborar o ensino, numa perspectiva antiga de organização de transmissão de conteúdos, será agora a perspectiva de desencadear nos alunos a atividade intelectual que thes permita criar sentido às aprendizagens e só assim, reelaborá-las e transformá-las em saberes [...]" (p. 14). ${ }^{2}$ Inevitavelmente, a passagem de um conteúdo científico para ser ensinável sofre transformações tanto é que se reconhece o "distanciamento" entre a origem do conhecimento e o resultado da mediação
} 
Com o entendimento que toda prática de ensino de um "fenômeno" ou "tema" a se fazer componente curricular (escolar) pressupõe de antemão a sua possível transformação prévia em objeto de ensino, é importante realçar a funcionalidade da mediação didática baseada nas características morfológicas e estilísticas dos saberes escolares, tais como: (1) predominância de valores de apresentação e de clarificação; (2) a progressividade possível de um conteúdo; (3) a divisão formal em módulos, unidades ou em capítulos; (4) aos comentários explicativos, glossários, vocabulários; (5) os meios da didatização a exemplos das ilustrações, esquematizações e exemplificação; dentre outros (VERRET, 1975; FORQUIN, 1993). Submetidos ao escrutínio exame, esses elementos configuram o espírito da cultura escolar que em contato com outros tipos de saberes advindos da própria comunidade onde a escola se insere responderia a outras problemáticas que não àquelas das instituições onde são produzidos os saberes de referência. Assim sendo, a referida cultura é prenhe de um conhecimento autêntico e original3.

Diante disso, desdobra-se a dimensão política a começar pela seleção dos conteúdos e, por extensão, às abordagens adotadas. Partindo-se do entendimento de que os conteúdos de ensino são frutos de uma seleção cultural e que elementos

educativa. Importante dizer que para a análise compreensiva dessas transformações há muitas teorias sobre a "didatização" do conhecimento cujos pressupostos são de perspectivas bem distintas. A Teoria da Transposição Didática é uma delas e um de seus ganhos é evidenciar processos como a despersonalização, a descontextualização, a desincretização (CHEVALLARD, 1991). No entanto, vale mencionar que sob o ponto de vista de outras teorizações, há críticas à ideia da transposição. Essa, por seu turno, não levaria em consideração os campos epistemológicos das áreas disciplinares (escolares) e nem que a própria mediação estaria atrelada a contextos sociais mais amplos. A produção escolar, especialmente aquela a partir do segundo segmento do ensino fundamental, é resultado e condicionante de um saber constituído por influências de saberes provenientes de diferentes atores sociais (CAILLOT apud MARANDINO, 2003) que travam disputas pela finalidade educacional, pelo sentido da formação educacional.

${ }^{3}$ Chervel fala, por exemplo, em "gramática escolar", pois a escola seria produtora de configurações cognitivas próprias e de habitus originais que constituiriam em grande parte a sua cultura: "[...] estas configurações cognitivas não podem ser consideradas, propriamente falando, nem como o reflexo nem como o substantivo de 'saberes de referência' em uso na vida social ou elaborados pelos profissionais do conhecimento científico ou erudito, mas constituem entidades culturais próprias, criações didáticas originais, que levam a recusar a imagem de uma escola fechada na passividade, de uma escola receptáculo de subprodutos culturais da sociedade [...]" (CHERVEL apud FORQUIN, 1992; p.35). 
sociopolíticos são fundamentais no jogo da "grade curricular", a atenção recai na objetividade desses conteúdos ensinados nas práticas pedagógicas. Serviriam ao quê? Para quê? Para quem? (SAVIANI, 2009).

Nesse jogo, não se evidencia que o "poder" de seleção seja equânime a todos os players do sistema didático (gestores dos sistemas de ensino, professores escolares, faculdades de formação de professores e universidades, comunidade científica) bem como também aos atuantes sindicatos, a opinião pública, os movimentos sociais. Os embates, acordos e dissonâncias entre os diferentes atores são elementos que comprovam a participação e capacidade desiguais de influenciar os pressupostos e objetivos educacionais nessa trama bastante capilarizada e repleta de tensionamentos. Ao mesmo tempo, vale dizer que a força da permanência de determinado conteúdo ou abordagem nas práticas curriculares em função da "tradição" escolar também vem revestida por um discurso ligado à "experiência" profissional dos docentes. Emerge daí a importância do desvelamento da disputa concernente à finalidade do ato educativo como expressão de um conjunto de interesses permeado por relações assimétricas em um determinado momento histórico.

A título de ilustração alguns dos resultados dessa trama podem elucidar as razões do sucesso ou fracasso da implementação de conteúdos e abordagens provocados por medidas ou políticas curriculares oficiais. O que se quer dizer é que (1) quando não bem acordado ou minimamente aceito entre os "jogadores" dos sistemas didáticos, não haverá decreto presidencial ou demanda social mesmo que provenha da própria comunidade escolar - que os legitimem e passem a fazer parte de maneira efetiva da sua cultura; (2) a formação docente não tem como característica a "homogeneidade" profissional a começar pelo campo disciplinar dos seus professores e das instituições que a engendram, apesar dos requisitos mínimos a se esperar pela formação inicial docente conforme preconizada nas Diretrizes Curriculares Nacionais implementadas até os dias hoje. 
Todavia, dentre a situação descrita e possíveis justificativas sobre as formas de trabalho dos professores de Geografia com o conteúdo em análise baseadas em distintos autores, compreende-se que muitas delas não estariam vinculadas exclusivamente aos fazeres docentes do formado em Geografia. Em verdade, baseando-se no escopo teórico-metodológico dessa preliminar investigação, as formas de trabalho pedagógico dos docentes estariam também condicionadas aos significados ou representações de um determinado conteúdo, aliás, atribuídos tanto por documentos curriculares oficiais quanto pelos valores epistemológicos e conceituais do corpus teórico disciplinar.

Dando sequência ao texto, antes de tomar conhecimento das representações da climatologia geográfica escolar dos professores, torna-se importante conhecer a versão curricular oficial, uma vez que a prática docente em muito está condicionada por esses documentos. A sua apresentação a seguir tem como referência a seguinte indagação: na provocação sobre as maneiras de trabalho pedagógico com a climatologia, os documentos curriculares apontam para quais sentidos do seu ensino?

\section{O QUE DIZEM OS DOCUMENTOS NORTEADORES?}

Os Parâmetros Curriculares Nacionais (PCN) direcionados à Educação Básica apresentam as diretrizes para a orientação dos conteúdos a serem desenvolvidos pelas disciplinas escolares, conforme os ciclos da Educação Básica. De antemão, dois esclarecimentos: (1) a climatologia não está apenas presente nos parâmetros da área concernente às ciências humanas ou da disciplina de Geografia; e (2) os estudos sobre o clima são apresentados em todos os anos escolares, inclusive no Ensino Médio.

Diferentemente de documentos anteriores, os PCN consagram a verificação e descrição dos fenômenos que constituem a climatologia como conhecimento. Confere-se que a grande valia pedagógica é explicar e compreender as interações 
entre a sociedade e natureza de modo processual situando-se em diferentes escalas espaciais e temporais, além de compará-las e conferindo significados através das contextualizações.

Em relação aos documentos correspondentes aos dois últimos ciclos da disciplina de Geografia, observa-se a disposição dos conteúdos em caráter relacional (Quadro 1 e Quadro 2). Em todos os eixos, a associação entre as ações sociais e a natureza se faz presente. Ao se seguir o consenso de que os conteúdos só fariam sentido na medida em que haja a construção de significados e sentido pelos alunos, exige-se do professor a mediação pedagógica adequada ao interpor o seu fazer aos conteúdos elencados à paisagem local e ao espaço vivido como referências para o seu trabalho pedagógico. 
Quadro 1 - Parâmetros Curriculares Nacionais (PCN) - conteúdo do terceiro ciclo do ensino fundamental II - Disciplina Geografia

\begin{tabular}{|c|c|}
\hline Eixo & Tema \\
\hline $\begin{array}{l}\text { Eixo 1- A Geografia como } \\
\text { possibilidade de leitura e } \\
\text { compreensão do mundo }\end{array}$ & $\begin{array}{l}\text { - A construção do espaço: os territórios e os lugares (o } \\
\text { tempo da sociedade e o tempo da natureza). } \\
\text { - A conquista do lugar como conquista da cidadania. }\end{array}$ \\
\hline $\begin{array}{l}\text { Eixo 2- O estudo da Natureza e sua } \\
\text { importância para o homem }\end{array}$ & $\begin{array}{c}\text { - Os fenômenos naturais, sua regularidade e } \\
\text { possibilidade } \\
\text { de previsão pelo homem- A natureza e as questões } \\
\text { socioambientais }\end{array}$ \\
\hline $\begin{array}{l}\text { Eixo } 3 \text { - O Campo e a Cidade como } \\
\text { formações socioespaciais }\end{array}$ & $\begin{array}{l}\text { - O espaço como acumulação de tempos desiguais } \\
\text { - A modernização capitalista e a redefinição nas relações } \\
\text { entre o campo e a cidade. } \\
\text { - O papel do Estado e das classes sociais e a sociedade } \\
\text { urbano-industrial brasileira. } \\
\text { - A cultura e o consumo: uma nova interação entre o } \\
\text { campo e a cidade }\end{array}$ \\
\hline $\begin{array}{l}\text { Eixo 4- A Cartografia como } \\
\text { instrumento na aproximação dos } \\
\text { lugares e do mundo }\end{array}$ & $\begin{array}{l}\text { - Da alfabetização cartográfica à leitura crítica e } \\
\text { mapeamento consciente. } \\
\text { - Os mapas como possibilidade de compreensão e } \\
\text { estudos } \\
\text { comparativos das diferentes paisagens e lugares. }\end{array}$ \\
\hline
\end{tabular}

Fonte: PCN (1998) http://portal.mec.gov.br/seb/arquivos/pdf/livro051.pdf / Acesso em: 12 de dezembro 2019. Quadro Elaborado pelos autores.

Os quadros destacados podem sugerir uma camisa-de-força para a prática docente. Em verdade, existe enquanto possibilidade a (re)organização dos conteúdos desde que os processos, conceitos e categorias citados sejam trabalhados. A depender da autonomização docente frente aos sistemas de ensino e das condições de trabalho oferecidos por esses mesmos sistemas e pela unidade escolar, o professor poderá contemplar a dinâmica climática em todos os eixos e assim abordar o conteúdo em tela de acordo com as diferentes escalas geográficas e com as temporalidades ao longo dos ciclos mencionados. 
No entanto, para que tal intento se realize de maneira efetiva consoante autores já citados deverá levar em consideração aspectos cruciais da "identidade" geográfica. A passagem a seguir do próprio documento em análise expressa:

[...] Sempre que tratar dos mecanismos do clima, da vegetação, dos solos e do relevo, deverá estar comprometido com uma visão metodológica do significado de todos esses processos naturais, com suas leis específicas, com suas diferentes formas de apropriação pela sociedade [...] (1998, p. 57).

Ao seguir com a análise, o segundo quadro apresenta os conteúdos agrupados no $4^{\circ}$ ciclo do estudo da Geografia com o intuito de que os alunos construam um conjunto de conhecimentos, referentes aos conceitos, aos procedimentos e às atitudes sobre os temas referentes à problemática ambiental.

Quadro 2 - Parâmetros Curriculares Nacionais (PCN) - conteúdos do quarto ciclo do ensino fundamental II - Disciplina Geografia

\begin{tabular}{|c|c|}
\hline Eixo & Tema \\
\hline $\begin{array}{l}\text { Eixo 1. A evolução das } \\
\text { tecnologias e as novas } \\
\text { territorialidades em Redes }\end{array}$ & $\begin{array}{l}\text { - A velocidade e a eficiência dos transportes e da comunicação } \\
\text { como novo paradigma da globalização. } \\
\text { - A globalização e as novas hierarquias urbanas }\end{array}$ \\
\hline $\begin{array}{l}\text { Eixo 2. Um só mundo em } \\
\text { muitos cenários geográficos }\end{array}$ & $\begin{array}{l}\text { - Estado, povos e nações redesenhando suas fronteiras } \\
\text { - Uma região em construção: o Mercosul } \\
\text { - Paisagens e diversidade territorial no Brasil }\end{array}$ \\
\hline $\begin{array}{l}\text { Eixo 3. Modernização, modos } \\
\text { de vida e a problemática } \\
\text { ambiental }\end{array}$ & $\begin{array}{l}\text { - O processo técnico-econômico, a política e os problemas } \\
\text { socioambientais. } \\
\text { - Alimentar o mundo: os dilemas socioambientais para a } \\
\text { segurança alimentar. } \\
\text { - Ambiente urbano, indústria e modo de vida. } \\
\text { - O Brasil diante das questões ambientais. } \\
\text { - Ambientalismo: pensar e agir }\end{array}$ \\
\hline
\end{tabular}

Fonte: PCN (1998) http://portal.mec.gov.br/seb/arquivos/pdf/livro051.pdf , Acesso em: 12 de dezembro 2019. Quadro elaborado pelos autores.

É no terceiro eixo do último ciclo que a climatologia pode ser trabalhada e potencialmente articulada entre as diferentes escalas geográficas sob à luz do 
ambientalismo e da modernização. Isso porque com uma mediação "problematizadora" por parte do professor talvez haja a possibilidade da tomada de posicionamento dos alunos perante os desafiantes problemas socioambientais.

Dando continuidade à investigação dos documentos oficiais, cabe mencionar a produção do Plano Municipal de Educação (PME), então em vigor, de Campos dos Goytacazes e a estrutura institucional da própria Secretaria de Educação. A propósito, no que diz respeito aos componentes curriculares da Educação Básica, a rede de ensino oficial campista apresenta-se de acordo com a Lei 11.274/2006, Artigo $15^{\circ}$, das Diretrizes Curriculares Nacionais, da referida etapa educacional, quando estabelece (I) Linguagens (Língua Portuguesa; Língua Materna, para as populações indígenas; Língua Estrangeira Moderna; Arte e Educação Física); (II) Matemática; (III) Ciências da Natureza; (IV) Ciências Humanas (História e Geografia) e, finalmente, (V) Ensino Religioso (BRASIL, 2006).

A Secretaria Municipal de Educação de Campos dos Goytacazes (SMECE), após o cumprimento das etapas orientadoras do Ministério da Educação (MEC) relativas à construção ou adequação dos seus planejamentos curriculares, iniciou o processo de adaptação curricular o qual foi publicado em Diário Oficial do Município datado em 15 de junho de 2015, através da Lei 8.653, que instituiu o novo Plano Municipal de Educação relativo ao decênio 2015-2025.

Para a construção desse Plano e das metas referentes à Educação Básica, contou-se com a participação de membros do governo, representantes da sociedade civil, Conselho Municipal de Educação (CME), Câmara Municipal, gestores de unidades de ensino e professores que, por sua vez, traçaram as metas para universalização do ensino fundamental, especificamente do segundo segmento, com intuito de fortalecer os projetos e atendimento ao ensino com vistas à melhoria dos índices educacionais. Assim, o atual documento foi reestruturado em consonância com o Plano Nacional de Educação (2014-2024) e a sua importância é o formal compromisso para a continuidade de políticas públicas 
que estabeleçam as metas e as estratégias para o serviço educacional do município. Sendo responsável pela Educação Básica, vale dizer que a citada Secretaria possui ainda como função as ações redistributivas em suas escolas e de autorizar, credenciar e supervisionar os estabelecimentos de seu sistema de ensino4.

As atribuições e competências da citada Secretaria foram estabelecidas conforme a Lei n8344/2013 e organizadas da seguinte forma: apoio ao docente, elaboração e orientação do Plano Político Pedagógico do municípios e das escolas, planejamento anual, discussões e auxílio na escolha dos livros didáticos, fomento à formação continuada, proporcionar cursos de capacitação, supervisão escolar , gerência de matrícula, atuação junto a unidades escolares, assistência administrativa e didática pedagógica aos professores, técnicos, profissionais de apoio pedagógicos, administrativo, mediante a realização de treinamentos (CAMPOS DOS GOYTACAZES, Lei n 8344, 13 de maio de 2013) 5.

A estrutura da Secretaria conta com os setores denominados Projetos e Convênios, o Gabinete do Secretário, Gerência de Serviço Social e a Gerência de Apoio Técnico, além do Gabinete do Secretário e a Subsecretaria Pedagógica. Nessa interinidade, as questões pertinentes ao planejamento anual das disciplinas escolares estão concentradas na Subsecretaria Pedagógica, composta por pedagogos, diretores e vice-diretores de escolas e creches, assistente escolar e as coordenações de áreas disciplinares referentes à educação básica (SMECE, 2019).

\footnotetext{
${ }^{4}$ Em termos gerais, a SMECE é a responsável pela política municipal de educação para os segmentos e modalidades de sua responsabilidade, a saber educação infantil, ensino fundamental (anos iniciais e finais) e educação de jovens e adultos, além dos trabalhos de planejamento, execução, supervisão, orientação, assistência social escolar e psicológica e controle da ação do governo, consoante à Lei de Diretrizes e Bases da Educação Nacional. Disponível em http://www.campos.rj.gov.br/atribuicoes/10.pdf . Acesso em 22 de outubro de 2019.

5 Para ter acesso às informações e dados sobre o quantitativo de professores (contratados e concursados), alunos e escolas do município, aplicação de questionário com professores, visitas às escolas, acesso a documentos referentes ao conteúdo da disciplina de Geografia do EFII assim como a devida autorização para a entrevista com a coordenação de área da rede municipal, protocolou-se o ofício no 14/2019 no setor de Protocolo da SMECE, no dia 12 de abril de 2019. Três dias depois, foi concedida a autorização da Secretaria para a realização da pesquisa a partir do contato com a coordenadora da área de Ciências Humanas e Diversidade, a qual se responsabiliza também pela disciplina de Geografia.
} 
Em entrevista realizada em 16 de maio de 2019, a Coordenadora de Ciências Humanas e Diversidade, Professora Aline Peixoto, confirma que compete à essa coordenação a realização das reuniões de planejamento no início de cada semestre letivo para as discussões e formulação acerca dos conteúdos que serão aplicados conforme as normativas propostas pelo Ministério da Educação (MEC), projetos e cursos de formação continuada ou em serviço, palestras, trabalhos de campo, feiras pedagógicas, sugestão de critérios para melhor embasamento teóricometodológico para a escolha dos livros didáticos por parte dos docentes.

Nesse mesmo contato, houve a disponibilidade dos materiais Planejamento Anual do conteúdo da disciplina de Geografia do ano letivo de 2019 bem como os critérios sugeridos para a escolha do livro didático no último triênio (2017-2019). Diante desses materiais e com a ciência que todas as áreas estão submetidas à Subsecretaria Pedagógica, as escolas da rede municipal de Campos dos Goytacazes que oferecem o segundo segmento do ensino fundamental somam 43 no total, incluindo as escolas municipalizadas em 2019: Escola Municipal Luiz Carlos Prestes, Escola Municipal Clóvis Tavares e Instituto Profissional São José.

Em relação aos incentivos de formação continuada dos docentes, a própria conta que a Secretaria está atenta a diversas questões que envolvem a formação docente. Por essa razão, a SMECE oferece cursos, seminários e palestras com renomados da área de ensino, porém não há cobertura de despesas com formações que venham a ocorrer fora da jurisdição municipal ou por outras instituições.

No tocante à escolha dos conteúdos da disciplina de Geografia, a entrevistada assegura que existe a participação dos docentes quando acontecem as reuniões de planejamento anual e frisa que tal escolha está condicionada às normativas do próprio Governo Federal, tais como Lei de Diretrizes e Bases (LDB), PCN, Diretrizes Curriculares Nacionais (DCN), Plano Nacional de Educação (PNE), Plano Municipal de Educação (PME). Sobre as obras didáticas, a Coordenação 
assume a tarefa da apresentação dos critérios avaliativos em caráter sugestivo, mas quem dá a palavra final seriam os professores de acordo com as realidades sociais onde atuam.

No entanto, os Projetos Político-Pedagógico (PPP) - municipal e escolar - não são acessíveis diretamente aos docentes. Para tanto, cada professor precisa solicitar o documento junto à SMECE e a sua elaboração fica a cargo da Subsecretaria Pedagógica.

Finalmente, com a confirmação da existência de canal de comunicação entre os professores e a coordenação, os desafios mais citados pelos profissionais da Educação em sua prática cotidiana são o "comportamento" dos alunos e a falta de materiais pedagógicos para o trabalho.

O documento denominado Planejamento Anual da SMECE condizente à disciplina de Geografia é confeccionado pela coordenadora em conjunto com os professores da área de Geografia. Tal documento é resultado do Encontro de Planejamento Anual realizado na Universidade Salgado de Oliveira (UNIVERSO) em 13 de fevereiro de 2019. Segundo a coordenadora Aline Peixoto, dentre os presentes estavam representantes da Coordenação de Ciências Humanas e Diversidade e alguns dos seus professores de Geografia. O objetivo foi discutir e apresentar o planejamento relativo à seleção de conteúdos a lecionar para cada ano escolar e a apresentação dos livros didáticos aprovados pelo MEC a partir de 2019.

A seleção de conteúdos é uma prática fundamental que diz respeito ao currículo, isto é, à formação de sujeitos e seus valores e visões de mundo em uma determinada sociedade. Currículo, portanto, está atrelado a contextos, ao tempo (processo), à composição das forças políticas em um determinado momento e ele não é menos contraditório, conforme já mencionado. Daí, depreende-se que as ações mais cotidianas como o ato da intervenção pedagógica enquanto combinação entre o encaminhamento metodológico adotado, objetivos educacionais, conteúdos e o desenvolvimento das habilidades cognitivas são ações 
curriculares. A escolha da metodologia e a finalidade educativa ou a "prática curricular" pode dizer muito sobre o posicionamento de um docente ou da comunidade escolar perante as grandes questões humanas.

É nesse sentido que o livro didático como recurso pedagógico também tem a sua importância quanto elemento das ações curriculares. Ele pode ser visto como ferramenta de auxílio no processo de ensino aprendizagem. Nesse sentido, Steinke (2015), tendo como referência os seus estudos sobre a climatologia escolar, salienta que mudanças significativas nas produções editoriais têm acontecido, principalmente em razão da Política Nacional do Livro Didático (PNLD), mas o seu uso pedagógico não necessariamente reflete rupturas com relação aos métodos clássicos de ensino.

O resultado do primeiro encontro do ano letivo de 2019 resultou em três prognósticos: Conteúdo, Habilidades e Estratégias6. Esse conjunto está organizado por Unidades Temáticas que, por sua vez, se desdobra em Objetos de Conhecimento e Habilidades. Dessa forma, identifica-se o conteúdo em investigação pelas proeminentes estações do ano, tipos de clima, circulação atmosférica, previsão do tempo. Contudo, há possibilidades de seu estudo com outros conteúdos.

Dentre os conteúdos e as habilidades explícitas na primeira parte do Planejamento, encontra-se: explicar as mudanças na interação humana com a natureza a partir do surgimento das cidades; diferenciar espaço urbano e rural; identificar as características das paisagens transformadas pelo trabalho humano a partir do desenvolvimento da agropecuária e do processo de industrialização;

\footnotetext{
${ }^{6}$ Bom voltar a dizer que o objetivo da pesquisa não é tornar ou propor a climatologia como o primordial conteúdo nos currículos do ensino fundamental, sobretudo nas escolas oficiais campistas e tão pouco a pretensão de que sugestões que porventura sejam propostas tenham a aplicabilidade ampla para as salas de aula. O ponto neste momento é a identificação do conteúdo da climatologia perante o programa curricular de Geografia para, mais adiante, problematizarmos as representações de seu ensino do ponto de vista dos docentes. Do ponto de vista do alunado, como sujeitos aprendentes e produtores do saber escolar, será contemplada na segunda e última parte da nossa pesquisa ainda a publicizá-la.
} 
reconhecer e identificar os valores do lugar, sentimentos, convívio no lugar onde se vive, as diferentes manifestações da natureza, sua apropriação e transformação pela ação da coletividade. Ainda, detectar possíveis problemas sociais e ambientais presentes no espaço onde se vive, identificando as causas para estimular a proposição de alternativas de resolução; perceber e compreender que o homem faz parte da paisagem e ao mesmo tempo a modifica, construindo assim o espaço geográfico (SMECE, 2019).

De saída, com a apresentação e comparação entre os lugares mediante os componentes físicos e humanos em diferentes escalas (temporal e espacial) seria possível associá-los aos diferentes tipos de clima, se partirmos do princípio de que " fundamentar-se em critérios que auxiliam o entendimento do clima como fator significativo que influencia a produção do espaço geográfico" (FERRETTI, 2009, p.13). Quanto à estratégia pedagógica, foram elencados a descrição do próprio cotidiano, pois, essa pode vir a favorecer a compreensão dos conceitos e sentidos de fenômenos como "ilhas de calor" ou "conforto térmico" (STEINKE, 2012; MAIA, 2010; FERRETTI, 2009).

No caso do planejamento correspondente ao $7^{\circ}$ ano, observa-se que as habilidades condicionadas aos conteúdos da climatologia não estão explícitas. Apesar disso, o caráter dos estudos regionais em escala nacional (macrorregiões, complexos regionais/regiões macroeconômicas ou os "quatro brasis") os quais formam a centralidade curricular do ano escolar em análise incorporam temas da dinâmica climática que, caso contrário, comprometeria, por exemplo, a compreensão do conceito "indústria da seca" ou ainda o "caracterizar dinâmicas dos componentes físico-naturais no território nacional, bem como a sua distribuição e biodiversidade" (SMECE, 2019).

Em relação ao $8^{\circ}$ ano, o planejamento orienta a associação da paisagem como produto de fatores sociais imbricados aos aspectos geomorfológicos, hidrográficos, da biogeografia e da climatologia na América Latina. Outros conteúdos climatológicos são renegados aqui a exemplo a atuação das massas de 
ar nesse recorte regional. No último ano escolar, a identificação e a comparação dos domínios morfoclimáticos nos demais continentes são as ações exigidas, embora não haja menção aos polos (SMECE, 2019).

Destarte, percebe-se que todos os anos escolares contemplam conteúdos da climatologia para apresentar a "geografia do mundo". De âmbito relacional, o clima é necessário para explicar o conceito de domínio morfoclimático. Todavia, instigante observar que o Planejamento Bimestral em análise não vislumbra a necessidade de caracterizar as abordagens dos estudos climáticos. Deduz-se que os colegas da disciplina podem decidir sobre as formas de apresentação dos estudos de tipos ou classificação climática a fim de identificar e comparar os domínios morfoclimáticos, habilidades exigidas ao longo do segundo segmento do ensino fundamental.

\section{COM A PALAVRA, OS PROFESSORES}

Já dito anteriormente que a rede oficial de educação de Campos dos Goytacazes possui mais de 40 escolas dedicadas ao segmento do ensino fundamental e disponibiliza vagas tanto para o ensino regular como para a modalidade de jovens e adultos. No tocante à quantidade de professores atuantes em salas de aula, contabiliza-se 87 professores dedicados à disciplina de Geografia para 8.396 alunos regularmente matriculados em 2019. Daqueles 87 docentes em efetivo exercício, pouco menos da metade (43) são concursados e os demais regidos por contratos temporários (SMECE, 2019).

Quanto à formação dos seus docentes, importante frisar que todos são provenientes de cursos de licenciatura em geografia. Desses cursos devidamente concluídos, constata-se a variedade de instituições formativas em suas trajetórias. Com essas características principais já informadas, pode-se definir que os sujeitos deste momento da pesquisa são os professores da disciplina de geografia tendo por base a sua vinculação com a Secretaria Municipal de Educação, Cultura e 
Esportes (SMECE) e que estivessem em atuação nas suas salas de aulas no ano letivo de 2019.

As informações analisadas foram obtidas graças à participação de alguns dos docentes. Por meio de entrevistas in loco, os profissionais forneceram os nomes das escolas onde trabalham, as respectivas cargas horárias, formação acadêmica, formação continuada, auto avaliação do domínio do conhecimento acerca da climatologia e demais conteúdos concernentes à disciplina de geografia, aos assuntos pedagógicos, acesso à Direção escolar e à própria Secretaria de Educação, aos documentos norteadores, participação na escolha de conteúdos e dos livros didáticos, tempo de vínculo com o magistério e com a SMECE de Campos dos Goytacazes, as possibilidades encontradas para a realização de cursos em formação continuada ligados ao campos educacional ou outros, além de outras informações.

Além das informações objetivas, outras informações foram obtidas graças às entrevistas as quais tiveram o caráter semi-estruturado "quando o entrevistador tem a liberdade para desenvolver cada situação em qualquer direção que consiste adequada. É uma forma que pode explorar amplamente a questão"(MARCONI; LAKATOS, 2008, p. 279). Dessa maneira, foi possível escutar os depoimentos dos professores pelas suas perspectivas e as expectativas, especificamente, com o ensino da climatologia em suas aulas. Outrossim, registrou-se as medidas institucionais encontradas para superação das dificuldades de aprendizagem quando constatadas tornando o seu ensino possível e os significados do conteúdo em destaque para a sua permanência como conhecimento escolar e para a disciplina de geografia.

A Teoria das Representações Sociais baseada nos estudos de Serge Moscovici (2012) tem como objetivo revelar as construções realizadas por determinados grupos sociais e as formas constituídas para a sua condução. Desse modo, é possível ponderar, inferir e compreender as ações engendradas por esses. A perspectiva aqui adotada é justificada pela crença de que os significados sociais 
podem contribuir para a formulação e implementação de políticas curriculares específicas, mormente aquelas dedicadas ao fomento e apoio às metodologias de ensino. De mais a mais, tal embasamento permite que os grupos focais possam participar das investigações tanto na condição de objetos bem como de sujeitos de pesquisa.

A observação direta também foi lançada mão como recurso metodológico. Em nome de uma relação face a face, as unidades escolares abriram as suas portas para a efetivação da técnica de observação não estruturada, assistemática, informal, livre, pois são qualidades as quais não exigem meios técnicos especiais ou perguntas "diretas" (MARCONI, LAKATOS, 2008, p. 192).

Dessa forma, do total de unidades, percorreu-se 27 escolas presentes no território campista. O tempo para tal pode ser considerado longo em relação ao previsto: em função, sobretudo da dificultosa mobilidade, o período de visitas às escolas e entrevistas perdurou sete meses ininterruptamente, ou seja, de abril a outubro de 2019.

Os critérios para o estabelecimento do grupo focal foi (1) a formação acadêmica, (2) professores efetivos ou contratados que estivessem lecionando nas turmas escolares de segundo segmento do ensino fundamental e com a (3) disciplina de geografia. Além dos documentos de autorização para a realização da investigação nas unidades escolares da SMECE, o termo de livre consentimento dos sujeitos a serem entrevistados também foi apresentado ao mesmo tempo explicado os pormenores do projeto de pesquisa denominada "Docência e Climatologia na Disciplina de Geografia do Segundo Segmento do Ensino Fundamental da Rede Municipal de Campos dos Goytacazes: uma aproximação (2018-2019)". Assim, obteve-se 21 entrevistas nessas condições, perfazendo 24,1\% do universo da pesquisa7.

\footnotetext{
${ }^{7}$ Nota-se a parcial colaboração dos colegas professores atuantes nessa rede oficial de ensino. Dentre os motivos alegados para a não participação da maioria, cita-se: $\left(1^{\circ}\right)$ "falta de tempo" (sem justificativa); $\left(2^{\circ}\right)$ Falta de tempo justificada pelo período e correção de trabalhos, testes, provas, além do preenchimento
} 
De um modo geral, depreende-se que o maior desafio para o fazer pedagógico por parte dos sujeitos dessa pesquisa não se restringe ao ensino da climatologia. Outros conteúdos também sofreriam com a falta do livro didático haja vista o déficit entre o que é disponibilizado pela SME e o número de alunos matriculados no citado segmento de ensino. Dos 21 professores entrevistados, 70\% relataram que não se verifica em suas salas de aula a relação "um livro por aluno". Aliás, segundo os próprios, esse é um problema recorrente e para amenizar a falta desse recurso didático a maioria docente expõe que: “[...] o material é elaborado pelo próprio professor, com bases em diferentes referências bibliográficas, elaboro o material e faço as escolhas [...]" (Professor $n^{\circ} 19$ ).

Especificamente a disciplina de Geografia também sofreria com a falta de apoio da "Prefeitura" para a realização de trabalhos de campo. Como parte de uma ação metodológica do processo de aprendizagem, as saídas "ao campo" proporcionariam facilidades entre "o que é visto em sala de aula e a realidade" (Professor $\mathrm{n}^{\circ}$ 7), principalmente quando se refere aos estudos climáticos (visitas à estação meteorológica; aulas-passeio em localidades de altitudes expressivas nos arredores do município; visitas aos campi universitários onde haja laboratórios de pesquisa voltados à climatologia; visitas a plenária da Câmara Municipal)8.

Sobre o conteúdo da Climatologia Geográfica, professores o remetem ao quão é desafiante o seu ensino, principalmente por causa dos elementos já citados anteriormente. Uma fala constante é que os seus alunos possuiriam grandes dificuldades, por exemplo, com a leitura e interpretação de gráficos tal como os climogramas. Ademais, a relação dos tipos de clima e a localização também é outro apontamento a fazer acerca das dificuldades.

\footnotetext{
de diários; $\left(3^{\circ}\right)$ não há razão ou "estímulo" para essa participação porque não haveria resultados "efetivos" dessas pesquisas para a melhoria das condições de trabalho e salários da categoria profissional.

${ }^{8}$ Embora não seja o foco desta pesquisa, não se pode preterir da análise geográfica entre as unidades escolares situadas em áreas rurais e urbanas. Pelas observações de campo e pelas falas dos entrevistados, a infraestrutura das escolas mais afastadas do principal núcleo urbano tende a contar com menos equipamentos pedagógicos quando se toma a comparação com aquelas que estão próximas a grandes eixos viários bem como as situadas no distrito-sede.
} 
Outros materiais são empregados pelos mesmos docentes do grupo focal. Enquanto recursos pedagógicos graças à mediação promovida pelos entrevistados, os artigos de jornais impressos e revistas auxiliam na aprendizagem dos alunos quando se diz respeito às mudanças climáticas “[...] a fim de correlacionar o dia a dia do aluno com os fatores e elementos do clima [...]" (Professor $n^{\circ}{ }^{12}$ ), ainda que os custos em grande parte fiquem por conta dos profissionais da educação.

No tocante à associação da climatologia e ao significado de cidadania, a totalidade de professores assegura que mediações didáticas são desenvolvidas a esse respeito, apesar de toda as dificuldades enfrentadas. O conteúdo em referência é importante para o entendimento dos fenômenos geográficos, especialmente no segmento em estudo porque "[...] é a parte da alfabetização para a vida no seu cotidiano, principalmente na identificação de áreas de risco [...]" (Professor $\mathrm{n}$ 014). O depoimento de uma entrevistada, por exemplo, ainda é mais enfático sobre os danos sociais e ambientais que acometem o município nos meses mais chuvosos e a importância do ensino da climatologia em suas aulas de Geografia: "[...] a climatologia é uma ferramenta que auxilia os alunos no enfrentamento deste problema e sua percepção para a diminuição dos perigos iminentes [...]" (Professor n²0).

De todo modo, chama atenção a irrelevância do registro da cidadania ou a sua problematização nos planos de aula e nos diários de classe, muito menos a correlação entre o seu significado no cotidiano local, categorias do saber geográfico e o conteúdo climatológico. Se de fato é trabalhado quando "longe" de gravadores, por que a omissão nos devidos registros bem como nas tarefas avaliativas?

Outra consideração na forma de resultado da pesquisa é a percepção dos docentes em sua totalidade sobre as dificuldades da mediação didática dos estudos climáticos. Segundo os próprios, os alunos escolares apresentariam dificuldades de aprendizagem relativas à conceituação e à capacidade explicativa 
do clima na constituição das paisagens. Sem mea culpa ou aviltamentos, os depoimentos dos entrevistados não deixaram margem para dúvidas de que acreditam que os seus processos formativos profissionais não teriam realçado ou dado o devido valor aos aspectos pedagógicos no mediar quando se trata de conteúdos, principalmente da geografia dos "aspectos físicos" entre o público escolar.

Esses aspectos acerca das dificuldades de ensino do conteúdo em questão vinculadas à infraestrutura escolar bem como da insuficiência de livros didáticos para todos os alunos escolares não é verificado exclusivamente ao grupo focal da disciplina em questão e muito menos na rede oficial campista. Por outro lado, a situação acaba por evidenciar a situação apreendida por esses sujeitos acaba por conformar a representação social do ensino da climatologia sob o enfoque geográfico. O total de 3/4 desses docentes em situar que o conteúdo em tela é de difícil "ensinagem" no segundo segmento do fundamental pode estar de acordo com aquelas apreensões, porém, ao mesmo tempo, com o percentual muito semelhante, $77 \%$ dos depoimentos recolocam que tais desafios estariam ligados de certa forma às questões curriculares das suas próprias formações acadêmicas. A título de ilustração, destaca-se a expressão do Professor n³: [...]"como não considerar tamanho esforço e tempo de preparo para um assunto que é tratado sem o devido tratamento pedagógico na minha graduação?[...]"

No que tange às abordagens da climatologia pelos professores de Geografia, igualmente salta aos olhos o uso das abordagens dinâmica e estática ao definir e classificar, por exemplo, os tipos de clima no estado fluminense, Brasil e no mundo. Por conseguinte, independe das escalas, isto é, dos anos escolares em que o emprego de uma ou outra abordagem sem a devida diferenciação é uma prática tomada, pois é "a que dá certo" (Professor n¹3). Conforme o embasamento teórico aqui assumido, não se afirma que seja um problema científico em si, pois trata-se da produção do conhecimento da climatologia de caráter escolar. No entanto, pelo material coletado, parece que os colegas de profissão tenham, sim, essa clareza. 
Por isso, vale pensar qual seria o desdobramento dessa postura pedagógica nas práticas educativas do segmento de nível médio quando de outras problematizações acerca das mudanças climáticas, por exemplo. Essa é uma das questões em aberto ao menos por enquanto.

Isso posto, concorda-se com Becker (1992) quando, na seara da epistemologia docente, ratifica a mistura de concepções e práticas contraditórias, por vezes, opostas ainda que não conscientes em nossas práticas docentes cotidianas. Nesse sentido, a produção da climatologia escolar, especificamente no segundo segmento do ensino fundamental não deixa de ser original e não necessariamente compromissada com a precisão e com o rigor metodológico como verificado nos cursos de formação superior. Logo, a representação do conteúdo climatológico na Geografia escolar desde que voltada à formação cidadã é considerada como de grande importância por mais de $60 \%$ dos docentes, mas os desafios de seu ensino estão correlacionados também ao teor pouco pedagógico quando da profissionalização nos cursos de formação docente.

\section{CONCLUSÃO}

A investigação abaliza que a percepção e práticas dos docentes com o conteúdo da climatologia no ensino fundamental do segundo segmento da realidade social em estudo está condicionada com contribuições não restritas aos saberes de referência ou científicos. Isso é deveras importante, pois o que se revela é que o entendimento do que seja "bom" ensino não se vincula exclusivamente à atualização do conhecimento, ou seja, conhecer novos termos do jargão científico seria condição sine qua non para o efetivo alcance dos objetivos educacionais, ao menos com os estudos do clima.

Embora essa constatação não signifique irrelevância das apreensões de novos conceitos ("efeito cascata"; "desextinção"; "refugiado climático"; "Princípio Antrópico"; "Eremoceno e Antropoceno"), os desafios para o ensino são anteriores 
sobre as pertinentes mediações pedagógicas do ponto de vista de quem ensina. De acordo com os mesmos, há inúmeras dificuldades enfrentadas para o processo de aprendizagem, mas não deixaram de indicar um certo "ressentimento" anterior à vida profissional, isto é, sugerem que as dificuldades pedagógicas encontradas com o conteúdo em análise possam estar na formação promovida pelas Licenciaturas.

Outras considerações ainda podem ser destacadas:

- Com a discussão da relação do componente clima com as propostas realizadas pelos professores em sala de aula, com o objetivo de evidenciar a importância deste componente da Geografia Escolar, todos compartilham a importância em evidenciar a relação entre sociedade natureza e a vivência do dia a dia dos alunos, pois como elemento natural afeta toda a sociedade. Todavia, quase totalidade dos entrevistados relataram que sabem da importância desta temática para a formação dos seus estudantes, mas, devido à carga horária de trabalho excessiva, à falta de recursos de multimídia, além da impossibilidade da realização do trabalho de campo e materiais básicos como folhas e livros, enfrentam dificuldades no processo de aprendizagem. O empenho da SMECE ainda não atende por completo as expectativas para um eficiente trabalho pedagógico.

- A falta de livro didático para todos os alunos em uma sala de aula é um empecilho ao trabalho docente. Alguns alunos não possuem os livros porque o número de exemplares enviado às escolas é sempre menor do que a quantidade de estudantes por sala. As alternativas dos profissionais de educação tem sido a confecção de seus próprios textos como recurso didático, embora, dentre os entrevistados, um tenha declarado que não "vê" importância no ensino de clima na geografia escolar e outro tenha revelado a dificuldade em explicar o conteúdo para os alunos por achar o componente clima similar à disciplina de Ciências. Essa foi a única representação social do conteúdo em análise destoante dos demais. Em termos gerais, os professores dessa pesquisa acreditam que não possuem formação e conhecimento que Ihes permitem abordar o componente clima de 
forma mais criativa, autônoma e significativa para os alunos mediante ao apoio escolar e do poder público.

- E, por último, de âmbito sugestivo por parte dos mesmos, é a participação mais ativa da SMECE com medidas de fomento e gerência de política pública como parcerias com as universidades a fim de fornecerem subsídios para a formação continuada e maior apoio material às escolas e a seus projetos pedagógicos.

\section{REFERÊNCIAS}

BARDIN, L. Análise de Conteúdo. Lisboa: Edições 70, 1977.

BECKER, F. Epistemologia subjacente ao trabalho docente. Porto Alegre: UFRGS/Faculdade de Educação, 1992.

BRASIL/LDB. Lei № 9.394, de 20 de dezembro de 1996. Estabelece as Diretrizes e bases da Educação Nacional. Disponível em: http://www.planalto.gov.br/ccivil_03/leis/L9394.htm. Acesso em: jan.2018.

BRASIL. Secretaria de Educação Fundamental. Parâmetros Curriculares Nacionais: Ensino Fundamental: Geografia. Brasília: MEC/SEF, 1998. Disponível em : http://portal.mec.gov.br/seb/arquivos/pdf/geografia.pdf. Acesso fev. 2018.

BRASIL. Secretaria de Educação Básica. Diretrizes Curriculares Nacionais Gerais para a Educação Básica. Brasília: MEC, SEB, DICEI, 2013. Disponível em: http://portal.mec.gov.br/docman/julho-2013-pdf/13677-diretrizes-educacao-basica-2013pdf/file. Acesso: fev. 2018

BRASIL. Senado Federal. Lei 10.172/01: Plano Nacional de Educação. Brasília, Senado Federal, 2001. Disponível em : http://www.planalto.gov.br/ccivil_03/leis/leis_2001//10172.htm. Acesso em 12 dez. 2018.

BRASIL. Secretaria de Educação Básica. Diretrizes Curriculares Nacionais Gerais para a Educação Básica. Brasília: MEC, SEB, DICEI, 2013. Disponível em : http://portal.mec.gov.br/docman/julho-2013-pdf/13677-diretrizes-educacao-basica-2013pdf/file. Acesso em 12 dez. 2018

BRASIL. Lei 9.394, de 1996. Regulamenta as Diretrizes e Bases da Educação Nacional. Diário Oficial [da] República Federativa do Brasil, Brasília, 1996. Disponível em: https://www2.senado.leg.br/bdsf/bitstream/handle/id/70320/65.pdf, acesso 15 de dez. 2018 
BRASIL. Ministério da Educação. Proposta de diretrizes para a formação inicial de professores da Educação Básica, em cursos de nível superior. 2000. Disponível em: http://portal.mec.gov.br/cne/arquivos/pdf/basica.pdf Último acesso em: 19 jan. 2019.

BRASIL Ministério da Educação, Conselho Nacional de Educação. Parecer CNE/CP 9/2001. Disponível em: http://portal.mec.gov.br/cne/arquivos/pdf/009.pdf, Acesso 19 de jan. 2019

BRASIL. Ministério da Educação, Conselho Nacional de Educação. Resolução CNE002/2002. Disponível em: http://portal.mec.gov.br/cne/arquivos/pdf/CP022002.pdf. Acesso em: 01 ago 2018.

CALLAI, H. C. A Geografia Ensinada e os Desafios de uma Educação Geográfica. In: MORAES, E. M. B. L. B. (Org.) Formação de Professores: conteúdos e metodologias no Ensino de Geografia. Jundiaí/São Paulo: Paco Editorial, 2010.

CAMPOS DOS GOYTACAZES. Plano Municipal De Educação, 2015. Disponível em file:///D:/Plano_Municipal_de_Educa\%C3\%A7\%C3\%A3o_2015-2025\%20(1).pdf Acesso em 11 out. 2018.

CAMPOS DOS GOYTACAZES. Lei $\mathbf{n}^{\circ}$ 8653, de 11 de junho de 2015. Disponível em: https://leismunicipais.com.br/a1/plano-municipal-de-educacao-campos-dos-goytacazes-rj. Acesso 13 out. 2018.

CAMPOS DOS GOYTACAZES. Decreto 226/2018. Disponível em https://www.campos.rj.gov.br/arquivos/DO/Mar-2019/DiarioOficialEletronicoEdicao-316.pdf. Acesso 15 abr. 2019.

CASTELLAR, S. M. V. A psicologia genética e a aprendizagem no ensino de Geografia. In: Castellar, S. M. V. (Org) Educação Geográfica: Teorias e Práticas Docentes, Ed. Contexto: São Paulo, 2006.

CAVALCANTI, L. S. (Org.). Temas da Geografia na Escola Básica. Campinas: Ed. Papirus, 2013. CHEVALLARD, Y. La transposición didáctica: del saber sábio al saber enseñado. Buenos Aires: Aique, 1991.

FERRETTI, E. Geografia em Ação, Práticas em Climatologia. Curitiba: Aymará, 2009.

FORQUIN, J. C. Escola e Cultura: as bases sociais e epistemológicas do conhecimento escolar. Trad. Guacira Lopes Louro. Porto Alegre: Artes Médicas, 1993.

FORTUNA, D. Climatologia Geográfica e Docência Escolar: um relato sobre as (im)possibilidades dos recursos pedagógicos no segundo segmento do ensino fundamental. Caderno de Estudos Geoambientais da Universidade Federal Fluminense, v.3, n.1, p.76-83, 2012

FORTUNA, D. Climatologia geográfica e os atlas escolares oficiais: limites e possibilidades da transposição didática. In: BEZERRA, A. C.; LOPES, J. J. M.; FORTUNA, D. (Org.) Formação de 
professores de Geografia: diversidade, prática e experiência. Niterói: Editora da UFF, 2015, v.1, p. 271-298.

GABRIEL, C. T. Usos e abusos do conceito de transposição didática - considerações a partir do campo disciplinar de História. In: IV Seminário Perspectivas do Ensino de História. Ouro Preto: UFOP, 2001.

LOPES, A. C. R. Conhecimento escolar em química: processo de mediação didática da ciência. Química Nova, v. 05, n²0, 1997, p. 52-82.

MAIA, D. C. Climatologia Escolar - saberes e práticas. São Paulo: Ed. Unesp Digital, 2018.

MARANDINO, M. Transposição ou recontextualização? Sobre a produção de saberes na educação em museus de ciências. Revista Brasileira de Educação. Rio de Janeiro, n²6, p. 95108, mai.-ago. 2003.

MARCONI, M. A.; LAKATOS, E. M. Fundamentos de Metodologia Científica. $6^{\text {a }}$ Ed. São Paulo: Atlas, 2009.

MARCONI, M. A.; LAKATOS, E. M. Metodologia Científica. 4. ed. São Paulo: Atlas, 2004.

MOSCOVICI, S. Representações Sociais: investigações em psicologia social. Petrópolis: Vozes, 2012.

PIMENTA, S. Cursos de Pedagogia: transgressões na formação de professores polivalentes In: Pimenta, S. G. et al (Orgs.). A Didática e os Desafios Políticos da Atualidade. Salvador: EDUFBA. 2019. p. 44-69.

PONTUSCHKA, N. N. A Geografia: pesquisa e ensino. In: CARLOS, A. F. A. (Org). Novos Caminhos da Geografia, Ed. Contexto, São Paulo, 1999.

PONTUSCHKA, N. N.; PAGANELLI, T. I.; CACETE, N. H. Para Ensinar e Aprender Geografia. Editora Cortez: São Paulo, 2007.

SANTOS, V. L. C.; ANDRADE, E. R. G.; XAVIER, M. D. D. Representações Sociais sobre a Pesquisa: um estudo com discentes-bolsistas do Pibic/UFRN do Curso de Pedagogia. In: V Encontro Nacional das Licenciaturas (ENALIC). Natal: UFRN, 2014.

SAVIANI, D. Formação de professores: as pectos históricos e teóricos do problema no contexto brasileiro. Revista Brasileira de Educação, v. 14, n 40, p. 143-155, jan-abr., 2009. Disponível em: http://www.scielo.br/pdf/rbedu/v14n40/v14n40a12.pdf. Acesso em: 25 dez 2020.

STEINKE, E. T. Climatologia Fácil. São Paulo: Oficina de Texto, 2012. 
STEINKE, E. T. Utilização da multimídia no ensino fundamental como instrumento de ensino de temas em Climatologia. Caminhos de Geografia. Universidade Federal de Uberlândia, v. 15, p. 127-139, 2014.

STEINKE, E. T. Conteúdos de climatologia na Geografia Escolar. In: RABELO, K. S. P.; BUENO, M. A. (Orgs.). Currículo, Políticas Públicas e Ensino de Geografia. Goiânia: Ed. da PUC Goiás, 2015.

VERRET, M. Les Temps des Étude. Lille: Editora Atelier Reproduction des Thèses/Université de Lille III, 1975.

WALLACE-WELLS, D. A Terra Inabitável: uma história do futuro. São Paulo: Companhia das Letras, 2019.

ZAVATTINI, J. A. A Climatologia Geográfica Brasileira, o enfoque e a noção de ritmo climático. Revista Geografia. Rio Claro, v. 23, n. 3, p. 5-24, 1998. Disponível em: https://www.periodicos.rc.biblioteca.unesp.br/index.php/ageteo/article/view/2261. Acesso em 18 jan. 2020.

\section{1 -Mayra Barros da Silva:}

Mestranda em Geografia - Univerdade Federal Fluminese https://orcid.org/0000-0003-0109-3168 - mayrabarros@id.uff.br Contribuição: De ambos autores em todas as fases do artigo.

\section{2 - Denizart Silva Fortuna:}

Doutor em Organização e Gestão do Território pela Universidade Federal do Rio de Janeiro

https://orcid.org/0000-0002-8672-328X - denizartfortuna@id.uff.br Contribuição: De ambos autores em todas as fases do artigo.

\section{Como citar este artigo}

SILVA, M. B. da; FORTUNA, D. S. Docência e climatologia na disciplina de Geografia do segundo segmento do ensino fundamental da rede municipal de educação de Campos dos Goytacazes: uma aproximação. Geografia Ensino \& Pesquisa, Santa Maria, v. 25, e44, p. 1-31, 2021. DOI 10.5902/2236499465161. Disponível em: https://doi.org/10.5902/2236499465161. Acesso em: dia mês abreviado. ano. 